Original Research Paper

\title{
Studies on Pharmacokinetics and Liver Microsome Metabolism of Nuciferine in Different Species of Animals
}

\author{
Dong Xiao-Chen, Liu Ming-Qi, Liu Jun, Guan Feng, Xu Ai-Chun, Zhao Jin and Ge Jian* \\ College of Life Sciences, China JiLiang University, Hangzhou, Zhejiang, 310018, China
}

\author{
Article history \\ Received: 07-05-2021 \\ Revised: 16-06-2021 \\ Accepted: 10-07-2021 \\ Corresponding Author: \\ Ge Jian \\ College of Life Sciences, China \\ JiLiang University, Hangzhou, \\ Zhejiang, 310018, China \\ E-mail: gejian16888@163.com
}

\begin{abstract}
This study aimed to compare the characteristics of pharmacokinetics and liver microsome metabolism among different species of animals including rabbit, rat and mouse and healthy New Zealand white rabbits, SPF Sprague Dawley (SD) rats and ICR mice were given intraperitoneal injection of nuciferine at a dose of $50 \mathrm{mg}$ per $\mathrm{kg}$ body weight. Blood samples were collected via caudal vein after administration and nuciferine concentrations in different points were determined by the method of HPLC-UV. Then the plasma concentration-time curves were drawn and the pharmacokinetics parameters were calculated by DAS 3.0 software. Besides, liver microsome from rabbit, rats and mice were prepared to study the metabolism of nuciferine in vitro. These results showed that nuciferine fitted two-compartment model in rabbits and rats and one-compartment model in mice. The calculated results of pharmacokinetics parameters showed that the fast absorption of nuciferine exhibited in rabbits, rats and mice, while the elimination was relatively slow. Compared with rabbits and rats, the nuciferine elimination was fastest in mice. The $\mathrm{Km}$ value of nuciferine metabolism in vitro was least in mice liver microsome, which suggested that the fastest metabolism of nuciferine existed in mice liver. Therefore, the pharmacokinetics characteristics of nuciferine in different species were significantly different, the elimination of nuciferine is the fastest in mice and the slowest in rabbits, which was in line with the in vitro metabolism trends by liver microsome from different species.
\end{abstract}

Keywords: Nuciferine, Pharmacokinetics, Liver Microsome Metabolism, Species Difference

\section{Introduction}

According to Chinese Pharmacopoeia, Lotus leaf (Nelumbo Nucifera Gaern) is a traditional Chinese medicine with a long history, which is mainly cultivated in southern China. The medicinal lotus leaf can be obtained by cleaning, cutting and drying (2015). Nuciferine is one of the main active ingredients in lotus leaves (Xu, 2021), which have good effects of reducing blood lipid (Ma et al., 2015), inhibiting hypercholesterolemia (You et al., 2014; Zhang et al., 2018), resisting cancer (Liu et al., 2015), inhibiting bacteria ( $\mathrm{Li}$ and $\mathrm{Xu}, 2007)$ and anti-tumor effects (Li et al., 2019). Lotus leaf can be used as both food and medicine, which belongs to the category of "medicine and food homology" and is widely used. Wang et al. (2008) studied the pharmacokinetics of nuciferine in beagle dog plasma by reverse high performance liquid chromatography. The results showed that nuciferine distributed rapidly in vivo and eliminated quickly. Liu et al. (2010) confirmed that nuciferine was distributed and eliminated rapidly in rat plasma by tail vein injection (Gu et al., 2014). Studies have shown that the pharmacokinetic parameters of nuciferine in rats, such as $t_{1 / 2 \beta}$ (elimination half-life) and $t_{\max }$ (peak time), are less often affected by the dose, while $\mathrm{C}_{\max }$ (peak concentration of plasma drug) and $\mathrm{AUC}_{0-\mathrm{t}}$ (area under the concentration-time curve) are directly proportional to the dose. However, there is no report on the differences of the pharmacokinetic characteristics of nuciferine in different species of animals.

Various active enzymes including CYP 450 are richest in liver, which is the main organ of drug metabolism. The most common model used for drug metabolism in vitro is the liver microsome and the metabolism characteristics of some drugs are usually evaluated in liver microsome in vitro (Ma et al., 2016; Xia et al., 2019). Certain study has shown that there is no significant species difference in the P450-catalyzed metabolism of nuciferine, while the 
glucuronidation product was only detected in microsome from humans and rabbits, which suggested that significant differences exited in glucuronosyltransferase-catalyzed metabolism in different species animals (Lu et al., 2010). However, the published experiment is only conducted from the correlation of liver microsomal enzymes in animals of different genera. As for the species-specific differences of metabolic rates in liver microsome, there is no published report. Therefore, the pharmacokinetics and in vitro metabolism rate of nuciferine was compared among rabbits, rats and mice, which aimed to clarify the pharmacokinetic differences of nuciferine in different species of animals from in vivo pharmacokinetic characteristics to in vitro liver microsome metabolism.

In lotus leaf, flavonoid components have also been prepared and used to pharmaceutical study except for lotus leaf-alkaloids in some literature, which suggested that pharmacological activities of lotus leaf maybe result from synthetic action including flavonoid and alkaloid products. And now, lotus leaf has always been used as dietic tea or other Chinese patent drug in China. Therefore, in order to clarify the drug safety and effectiveness in human, it would be very significant to reveal the pharmacokinetics difference of nuciferine from different species animals. And these above studies should be helpful to extrapolate the effectiveness and safety from experimental animal to human.

\section{Materials and Methods}

\section{Animals}

SD rats $(300 \pm 50 \mathrm{~g})$ and ICR mice $(20-40 \mathrm{~g})$ were purchased from Shanghai Experimental Animal Co., Ltd., with animal license number SCXK (Shanghai) 2017-0005. The New Zealand white rabbits $(2.6 \pm 0.5 \mathrm{~kg})$ was purchased from Hangzhou Yuhang Kelian Rabbit Industry Professional Cooperative with license number SCXK (Zhejiang) 2017-0004. Before animal treatment, all animals were housed in our experimental animal center and provided with sterilized tap water and granule feed $\mathrm{ad}$ libitum. Room temperature was maintained at $25^{\circ} \mathrm{C} \pm 2{ }^{\circ} \mathrm{C}$ with a relative humidity of $65 \pm 15 \%$ and a day/light cycle of $12 \mathrm{~h}$. And these animal experiments protocol was approved according to the agreement of Laboratory Animal Ethics Committee from China Jiliang University.

\section{Reagents and Instruments}

The standard product of nuciferine was purchased from Sichuan Weikeqi Biotechnology Co., Ltd. (purity $\geq 98 \%$ ). Isoimperatorin was purchased from Shanghai Yuanye Biotechnology Co., Ltd. (purity $\geq 98 \%$ ). Chromatographic acetonitrile was purchased from Shanghai Spectrum Chemical Co., Ltd. Chromatographic methanol was purchased from Shanghai Macklin Biochemical Technology Co., Ltd. Ethyl acetate was analytically pure and purchased from Hangzhou Gaojing
Chemical Co., Ltd. The HPLC system used in this research was SHIMADZU-20AT series equipment, with a UV detector and a Zhida N 2000 instrument workstation written by Zhejiang University.

\section{RP-HPLC Method}

The HPLC system is shimadzu 20AT (Shimadzu, Japan), the chromatographic column is Discovery SUPELCO ODS C18 column $(5 \mu \mathrm{m}, 150 \times 4.6 \mathrm{~mm})$, the guard column is Agilent ODS C18 column $(5 \mu \mathrm{m}, 12.5 \times 4.6 \mathrm{~mm})$ and the mobile phase is composed of acetonitrile and $0.1 \%$ triethylamine (50: $50, \mathrm{v} / \mathrm{v})$. The column temperature was kept at $35^{\circ} \mathrm{C}$ and the detector wavelength was set at 270 $\mathrm{nm}$. The flow rate was $1.0 \mathrm{~mL} / \mathrm{min}$. Then $20 \mu \mathrm{L}$ were injected directly into the RP-HPLC system.

$200 \mu \mathrm{L}$ of blank plasma or liver microsomal homogenate was added with $20 \mu \mathrm{L}$ of isoimperatorin (100 $\mu \mathrm{g} / \mathrm{mL})$ and $20 \mu \mathrm{L}$ of serial nuciferine standard solutions (1.0, 5.0, 10.0, 50.0, 100.0, 500.0 mg/L). The tube was vortex-mixed for $1 \mathrm{~min}$, then $3 \mathrm{~mL}$ ethyl acetate was added. After centrifugation $(5000 \mathrm{r} / \mathrm{min}$ ) for $5 \mathrm{~min}$, the organic phase was transferred to a glass test-tube. All the organic phase were evaporated to dryness at $45^{\circ} \mathrm{C}$ under a stream of nitrogen gas. The residue was reconstituted with $100 \mu \mathrm{L}$ methanol, centrifuged again for $5 \mathrm{~min}(10000 \mathrm{r} / \mathrm{min})$ and $20 \mu \mathrm{L}$ of supernatant was inlet into HPLC system.

The Quality Control samples (QC) of nuciferine plasma and liver microsome were prepared at high, medium and low concentrations $(50,5$ and $0.5 \mathrm{mg} / \mathrm{L})$. The sample was treated by the method as the same above and five repeats were performed for each concentration. The extraction recovery at different concentrations was calculated by the ratio of the peak area in the treated sample to the peak area of nuciferine directly dissolved in chromatographic methanol. Intra-day and inter-day precisions were calculated according to the nuciferine areas from the same quality control samples and the Relative Standard Deviation (RSD, \%) was calculated by comparing the peak area changes measured five times. At the same time, the peak area ratio of spiked samples was substituted into the standard curve equation and the nuciferine concentration was calculated. By comparison of the calculated concentrations of spiked samples with the added concentration, the accuracy (\%) of the HPLC-UV method was obtained.

The Quality Control samples (QC) with concentrations of $0.5,5.0$ and $50.0 \mathrm{mg} / \mathrm{L}$ were also prepared and stored at room temperature, 4 and $-20^{\circ} \mathrm{C}$, respectively and all these samples were processed according to the above-mentioned method and the samples with each concentration were injected for 5 repeats. The detected peak area ratio of these samples was substituted into the standard curve equation and the ratio of the obtained concentration to the added concentration was calculated, which was used to characterize the nuciferine stability in plasma and liver microsome. 


\section{Sample Collection}

The New Zealand white rabbits were fixed on a constant temperature holding table. After depilation, indwelling needles were placed in femoral vein. The quaternized chitosan nanoparticle solution of nuciferine was injected Intraperitoneal at a dose of $50 \mathrm{mg} / \mathrm{kg}$ body weight and blood samples were collected at 5, 10, 20, 30 and $45 \mathrm{~min}, 1,2,3,6$, 10 and $24 \mathrm{~h}$ after administration, respectively. Rats and mice were also intraperitoneally administered and blood was collected at the same points as above. And the plasma was centrifuged at $5000 \mathrm{r} / \mathrm{min}$ for $5 \mathrm{~min}, 200 \mu \mathrm{L}$ plasma was absorbed and added into a blank tube with an addition of 20 $\mu \mathrm{L}$ isoimperatorin solution as internal standard. According to the prepared method above mentioned, plasma was arrayed and $20 \mu \mathrm{L}$ supernatant was taken for analysis.

\section{Liver Microsome Preparation}

According to published literature (Feng et al., 2020), the preparation method was partly changed. The liver microsome were prepared by the use of $0.15 \mathrm{~mol} / \mathrm{L} \mathrm{KCL-0.2}$ $\mathrm{mol} / \mathrm{L}$ sucrose solution $(\mathrm{pH} 7.5)$ and $0.05 \mathrm{~mol} / \mathrm{L}$ Tris- 0.25 $\mathrm{mol} / \mathrm{L}$ sucrose solution ( $\mathrm{pH} 7.5)$, which were labeled as solution I and solution II, respectively. Animal livers were washed with solution I in order to remove blood attached to liver surface, absorbed water with filter paper and weighed. After cutting, liver tissue was homogenized with homogenizer in ice bath. Then the homogenate centrifuged for 20 mins $\left(10000 \times \mathrm{g}, 4^{\circ} \mathrm{C}\right)$ and for $60 \mathrm{~min}(105000 \times \mathrm{g}$, $4^{\circ} \mathrm{C}$ ), respectively and the reddish precipitate in the lower layer was liver microsome. Then the microsome were resuspended with solution II and the protein concentration was measured according to BCA kit. The protein concentrations of liver microsome were 5.81, 34.54 and $22.12 \mathrm{mg} / \mathrm{mL}$ in rabbit, rat and mouse, respectively and these micro some were diluted to $1 \mathrm{mg} / \mathrm{mL}$ with $1 \times \mathrm{PBS}$ for use.

\section{In vitro Metabolism in Liver Microsome}

The NADP reaction system consists of $1.0 \mathrm{mmol} / \mathrm{L}$ NADP, $100 \mathrm{mmol} / \mathrm{L}$ phosphate buffer and $4.0 \mathrm{mmol} / \mathrm{L}$ $\mathrm{MgCl}_{2}$. The protein concentration of liver microsomes of the three animals was $1.0 \mathrm{mg} / \mathrm{mL}$ and the concentration of nuciferine standard solution is 12.5, 25, 50, 100, 200 and 400 $\mu \mathrm{M}$ in the reaction system, respectively. After the reaction was started, it was incubated at $37^{\circ} \mathrm{C}$. After reaction for one hour, $200 \mu \mathrm{L}$ frozen acetonitrile was added to stop the reaction. Then $20 \mu \mathrm{L}$ isoimperatorin was added into the reaction system, which was treated by the method above mentioned and analyzed by HPLC. The Line Weaver-Burk equation was used to calculate kinetic values (Vm and $\mathrm{Km}$ ).

\section{Data Analysis}

The results of all test datas were expressed by mean standard deviation and the differences were analyzed by SPSS 18.0 software. $\mathrm{P}<0.05$ indicated significant differences.

\section{Results}

\section{Chromatogram and Specificity Analysis}

Under the selected chromatographic analysis conditions, nuciferine and impurities are well separated by comparing the chromatograms generated from standard solution samples (Fig. 1A), blank microsome (Fig. 1B), blank microsome with standard solution (Fig. 1C) and microsome metabolism (Fig. 1D). It suggests that nuciferine and the internal standard is operator in had no interference peaks at the corresponding retention times, which are at 13.727 and 24.257 min respectively.

\section{Standard Curve}

All the nuciferine concentrations were set at $0.1,0.5$, $1,5,10$ and $50 \mathrm{mg} / \mathrm{L}$ respectively. After being treated according to method above, $20 \mu \mathrm{L}$ sample was used for analysis. The regression equation of the curve and correlation coefficients $(r)$ were calculated as followed:

$$
\begin{aligned}
& \text { Plasma }: Y=0.0115 X+0.0007(r=0.9999) ; \text { Liver } \\
& \text { microsome }: Y=0.0138 X+0.0023(r=0.9998)
\end{aligned}
$$

\section{Validation of Nuciferine}

The average recovery of nuciferine in plasma was higher than $90.0 \%$, the intra-day and inter-day coefficients of variation were both lower than $10.0 \%$ and the accuracy was higher than $95.0 \%$, which indicated that the recovery of nuciferine in plasma was good, with good precision and accuracy (Table 1), which could fully meet the requirements of this experiment. At the same time, 0.5, 5.0 and $50 \mathrm{mg} / \mathrm{L}$ nuciferine solution was selected and stored at room temperature, 4 and $-20^{\circ} \mathrm{C}$, respectively and the stability of nuciferine under different storage conditions was calculated. The results showed that nuciferine was stable in plasma and had significant metabolism in liver microsome (Table 2).

\section{Pharmacokinetics of Nuciferine in Different Animals}

According to the HPLC quantitative analysis method established in this experiment, the ratio of the peak area of nuciferine in plasma at different time points to the peak area of the internal standard isoimperatorin was substituted into the standard curve equation and the plasma concentration of nuciferine at different time points was calculated. According to the plasma collection time and nuciferine concentration of animals of different species, draw the plasma concentrationtime curve, as shown in Fig. 2.

The pharmacokinetic parameters were calculated by pharmacokinetic software, which were listed in Table 3. The absorption half-life $\left(\mathrm{t}_{1 / 2 \mathrm{Ka}}\right)$ of nuciferine in three animals was $0.19 \mathrm{~h}$ in mice, $0.14 \mathrm{~h}$ in rabbits and $0.12 \mathrm{~h}$ in rats, which indicated that nuciferine absorbed rapidly in three animals. The elimination half-life $\left(t_{1 / 2 \beta}\right)$ of nuciferine in rabbit, rat and mouse plasma were 17.41 , 
7.44 and $2.16 \mathrm{~h}$, respectively, indicating that nuciferine was eliminated fastest in mice. The AUC values of the area under the plasma concentration-time curve in different animals were $121.00,39.06$ and 3.97 $\mathrm{mg} \cdot \mathrm{h} \cdot \mathrm{L}^{-1}$ and the AUC in rabbits was much higher than that in rats and mice, indicating that the relative dwelling of nuciferine in rabbit was highest during the administration time.

Table 1: Recovery, accuracy and precision of nuciferine in plasma and liver microsome $(n=5)$

\begin{tabular}{lcllll}
\hline & & & & \multicolumn{2}{c}{ Precision $(\%)$} \\
Concentrations $(\mathrm{mg} / \mathrm{L})$ & Recovery $(\%)$ & Accuracy $(\%)$ & inter-day \\
\hline Plasma & 0.5 & $96.90 \pm 1.26$ & $97.31 \pm 5.38$ & 4.34 & 6.74 \\
& 5.0 & $98.45 \pm 0.63$ & $100.48 \pm 6.56$ & 2.71 & 7.67 \\
Microsome & 50.0 & $99.12 \pm 0.66$ & $98.71 \pm 4.66$ & 2.22 & 6.67 \\
& 0.5 & $96.25 \pm 1.14$ & $98.58 \pm 3.04$ & 7.41 & 8.48 \\
& 5.0 & $98.69 \pm 0.89$ & $98.36 \pm 6.17$ & 3.69 & 8.25 \\
\end{tabular}

Table 2: Stability of nuciferine in plasma and liver microsome $(n=5)$

\begin{tabular}{llll}
\hline \multirow{2}{*}{ Concentrations $(\mathrm{mg} / \mathrm{L})$} & Storage conditions & Stability $(\%)$ & Microsome \\
\hline 0.5 & Room temperature & $96.16 \pm 1.72$ & $70.91 \pm 5.82$ \\
& $4{ }^{\circ} \mathrm{C}$ & $98.03 \pm 0.97$ & $93.68 \pm 2.96$ \\
5.0 & $-20^{\circ} \mathrm{C}$ & $98.32 \pm 0.87$ & $98.27 \pm 0.86$ \\
& Room temperature & $96.78 \pm 1.59$ & $88.35 \pm 2.67$ \\
& $4{ }^{\circ} \mathrm{C}$ & $98.08 \pm 1.27$ & $97.88 \pm 1.38$ \\
50.0 & $-20^{\circ} \mathrm{C}$ & $98.67 \pm 1.6$ & $98.60 \pm 1.13$ \\
& Room temperature & $98.66 \pm 0.67$ & $89.19 \pm 6.73$ \\
& $4{ }^{\circ} \mathrm{C}$ & $98.54 \pm 2.79$ & $98.318 \pm 2.75$ \\
& $-20^{\circ} \mathrm{C}$ & $98.26 \pm 3.36$ & $98.14 \pm 3.29$ \\
\hline
\end{tabular}

Table 3: Pharmacokinetics parameters of nuciferine in three animals $(\mathrm{n}=5)$

\begin{tabular}{llll}
\hline Parameters & Rabbits & Rats & Mice \\
\hline $\mathrm{t}_{1 / 2 \mathrm{ka}} / \mathrm{h}$ & 0.14 & 0.12 & 0.19 \\
$\mathrm{t}_{1 / 2 \alpha} / \mathrm{h}$ & 0.21 & 0.15 & $/$ \\
$\mathrm{t}_{1 / 2 \beta} / \mathrm{h}$ & 17.41 & 7.44 & 2.16 \\
$\mathrm{~T}_{\max } / \mathrm{h}$ & $/$ & $/$ & 0.74 \\
$\mathrm{C}_{\max } / \mathrm{mg} \cdot \mathrm{L}^{-1}$ & $/$ & $/$ & 1.00 \\
$\mathrm{AUC} / \mathrm{mg} \cdot \mathrm{h} \cdot \mathrm{L}^{-1}$ & 121.00 & 39.06 & 3.97 \\
$\mathrm{~V}_{\mathrm{d} / \mathrm{F}} / \mathrm{L} \cdot \mathrm{kg}^{-1}$ & 10.38 & 13.74 & 39.32 \\
$\mathrm{CL} \mathrm{T} / \mathrm{F} / \mathrm{L} \cdot \mathrm{min}^{-1}$ & 0.41 & 1.28 & 12.60 \\
\hline
\end{tabular}

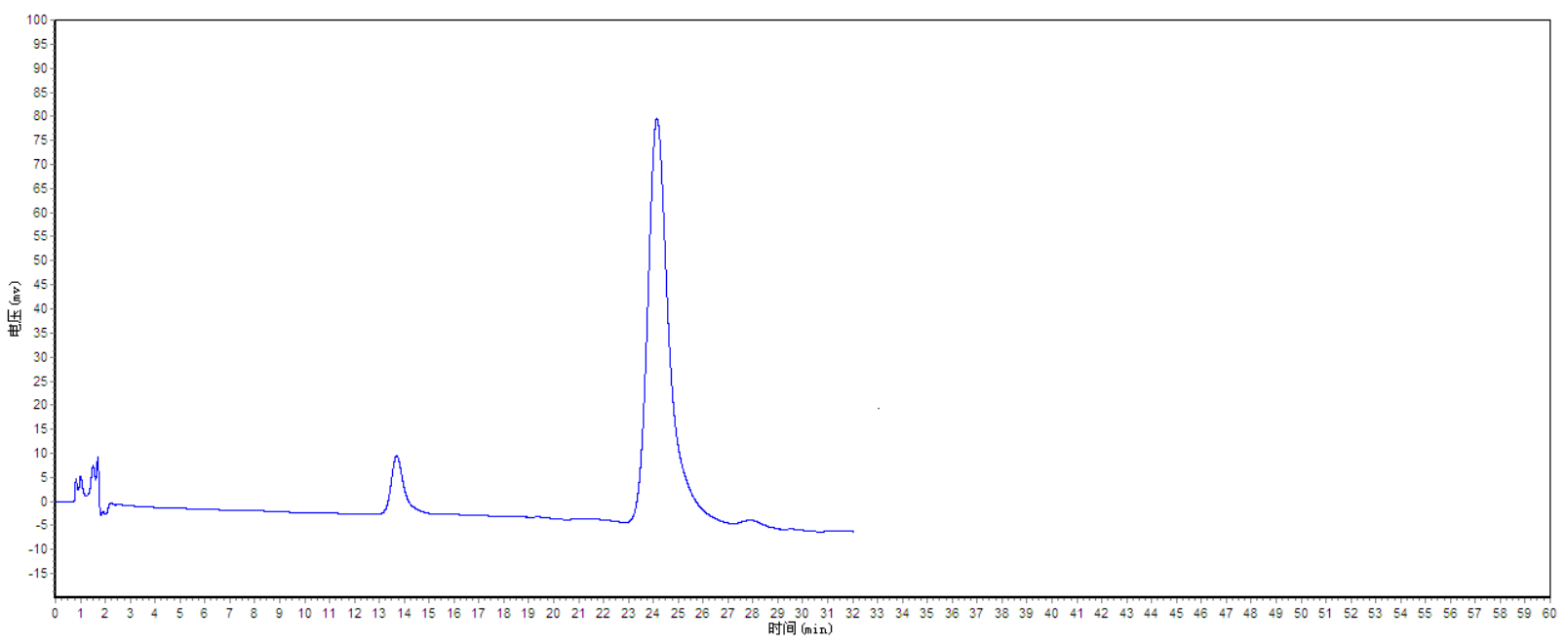




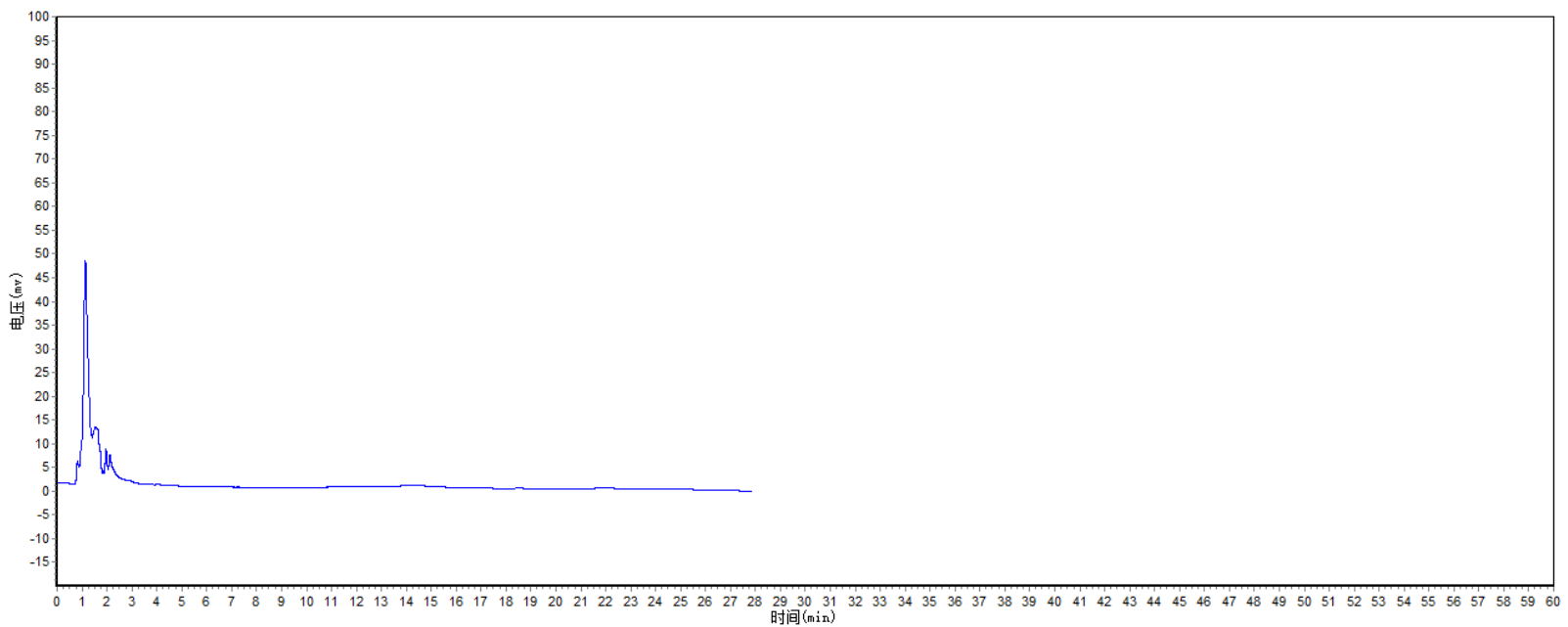

(b)

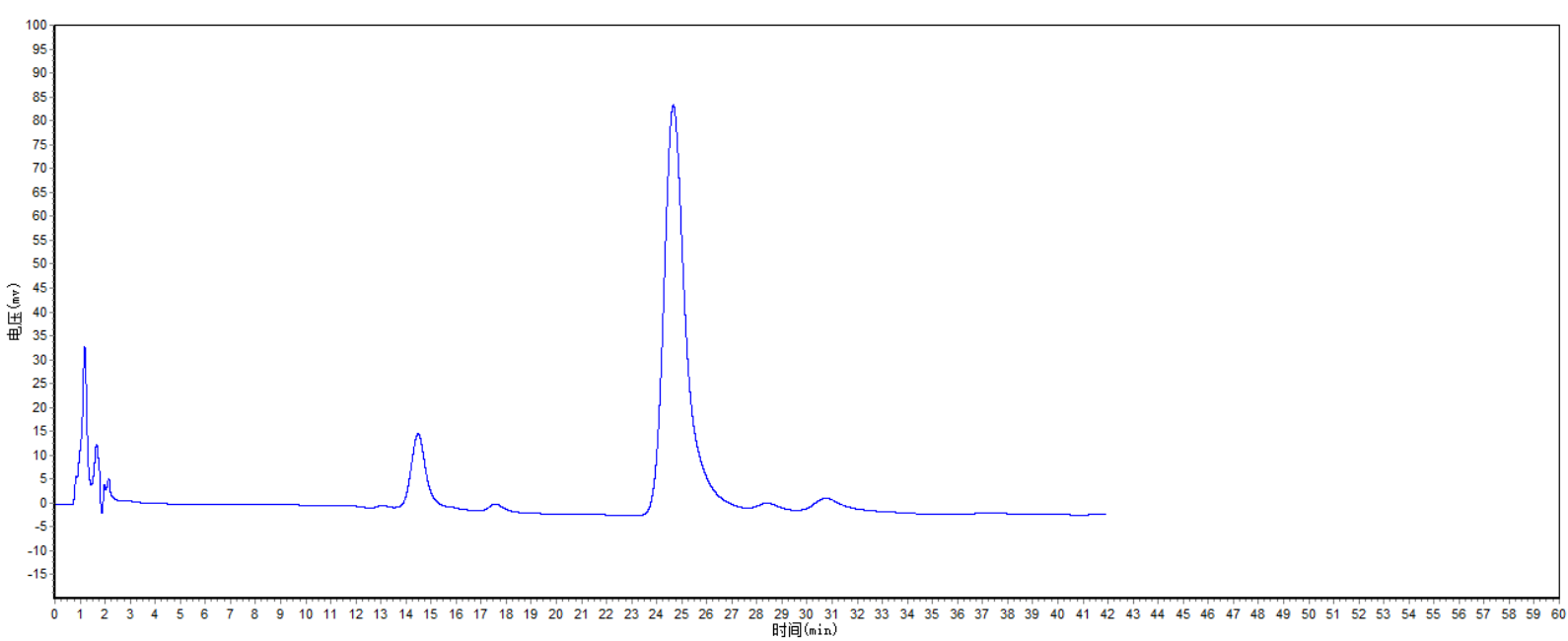

(c)

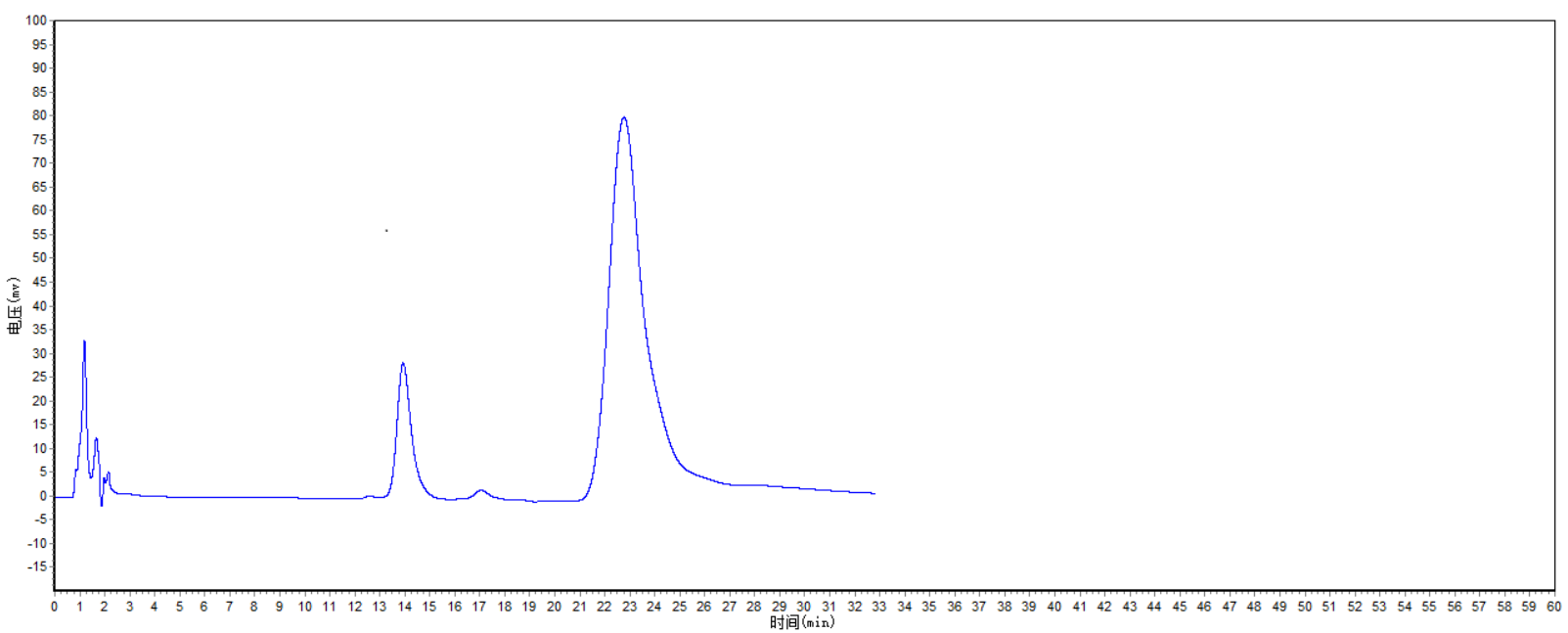

(d)

Fig. 1: Chromatograms of nuciferine generated from: (A) Standard chromatogram; (B) blank liver microsome; (C) blank microsome with standard solution of nuciferine; (D) samples from microsome metabolism. Peak 1: Nuciferine Peak 2: Internal Standard 
Dong Xiao-Chen et al. / American Journal of Biochemistry and Biotechnology 2021, 17 (3): 320.327 DOI: 10.3844/ajbbsp.2021.320.327
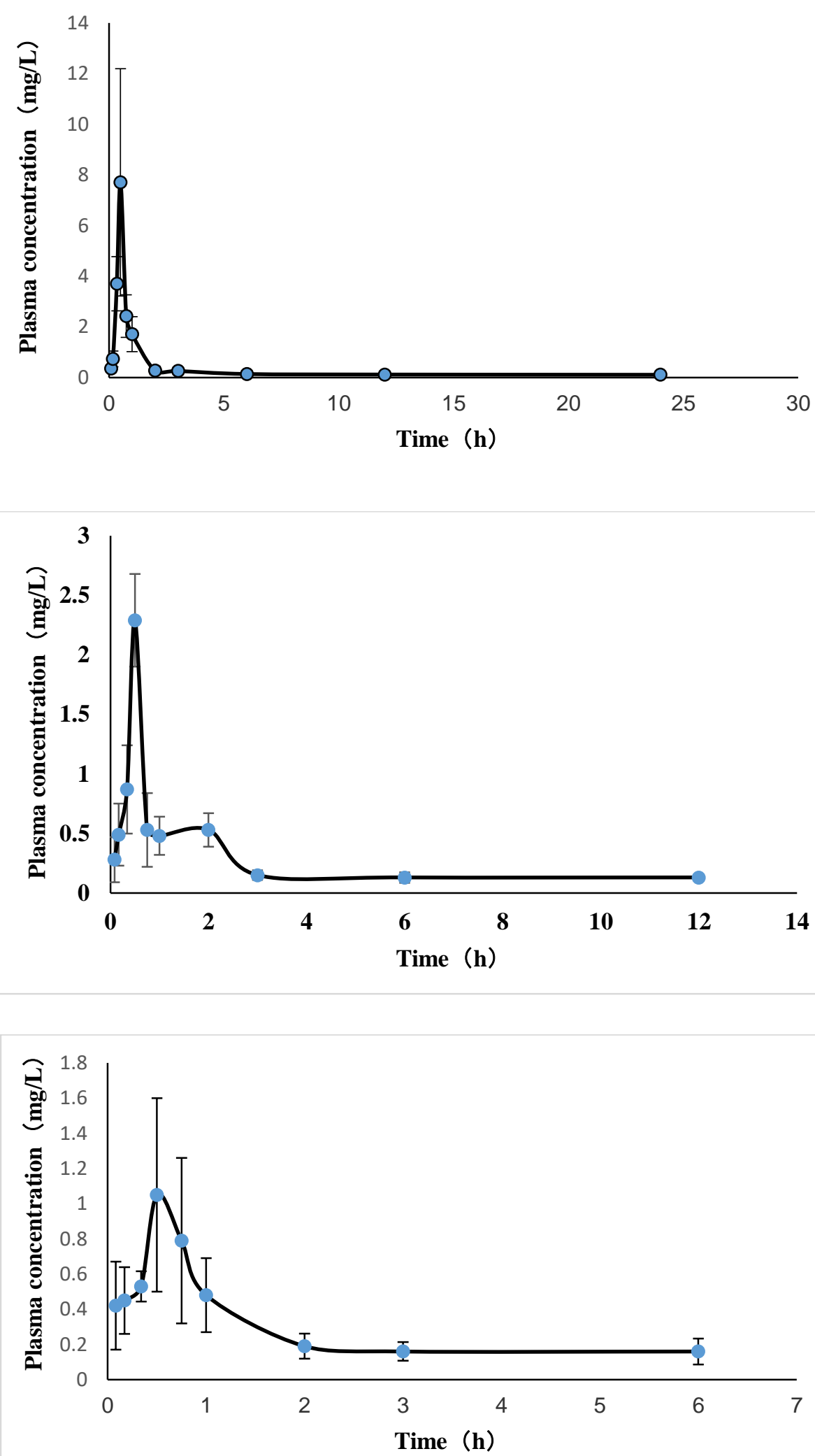

Fig. 2: Plasma concentration-time curve of nuciferine in rabbits, rats and mice A: Rabbits; B: Rats; C: Mice 


\section{Metabolic Characteristics of Nuciferine in Liver Microsome}

The metabolic characteristics of nuciferine in liver microsome of different species were compared and the Vm values of nuciferine in liver microsome of rabbits, rats and mice were calculated as $1.20 \pm 0.61 \mathrm{mg} /(\mathrm{h} \cdot \mathrm{L}), 1.64 \pm 0.87$ $\mathrm{mg} /(\mathrm{h} \cdot \mathrm{L})$ and $0.12 \pm 0.02 \mathrm{mg} /(\mathrm{h} \cdot \mathrm{L})$, respectively. At the same time, the $\mathrm{Km}$ values of nuciferine were calculated to be 207.01 $\pm 109.19 \mathrm{mg} / \mathrm{L}, 126.22 \pm 59.09 \mathrm{mg} / \mathrm{L}$ and $35.17 \pm 1.05$ $\mathrm{mg} / \mathrm{L}$, respectively and the $\mathrm{Km}$ value of nuciferine in mouse liver microsome was the smallest, which indicated that nuciferine had strong binding action with metabolic enzymes in mouse liver microsome.

\section{Discussion}

According to the pharmacokinetics parameters of different animals, the absorption of nuciferine in three animals is fast and the absorption half-life is short. The result of elimination half-life was rabbit $>$ rat $>$ mouse and AUC values from high to low was rabbit $>$ rat $>$ mouse. $\mathrm{Li}$ et al has calculated the $\mathrm{t}_{1 / 2 \beta}, \mathrm{Vd}, \mathrm{CL}$ and $\mathrm{AUC}_{0 \text {-inf }}$ in rats by intravenous injection, which were $(1.73 \pm 0.58) \mathrm{h}$, $(5.03 \pm 0.24) \mathrm{L} / \mathrm{kg},(4.23 \pm 0.78) \mathrm{L} \cdot \mathrm{h}^{-1} \cdot \mathrm{kg}^{-1}$ and $(2.35 \pm 0.46)$ $\mathrm{mg} \cdot \mathrm{L}^{-1} \cdot \mathrm{h}$ respectively $(\mathrm{Gu}$ et al., 2014) and these were quite different from our experiment results, which may be due to the fact that the administration route in this study is intraperitoneal injection and the injection of nuciferine nanoparticles encapsulated by quaternized chitosan has significant slower release function.

After injection, nuciferine first pass through the liver and then distribute to the whole body. The liver is rich with a variety of drug metabolism enzymes, which is the main place for the metabolism of a variety of drugs (Xia et al., 2019). However, the organs and tissues of body are complex, so it is difficult to directly study and elucidate the pharmacokinetic characteristics of drugs in vivo. In vitro, liver microsome experiment has the advantages of simple operation and easy collection of samples (He et al., 2021). Certain published literature has compared the differences of metabolic enzymes of nuciferine in different species of liver microsome (Lu et al., 2010), in which only metabolic enzymes of nuciferine from liver microsome of different species animal were studied, but not involving the study of the metabolic rate of nuciferine in different liver microsome. Therefore, the in vitro metabolic differences of nuciferine were studied in rabbits, rats and mice liver microsome. The results confirmed that the $\mathrm{Km}$ values of nuciferine metabolism in liver microsome were rabbit $>$ rat $>$ mouse $(p<0.05)$. Km value is an important parameter of enzyme metabolism reaction in vitro, which indicates the substrate concentration when metabolic rate of nuciferine reaches half of the maximum metabolism rate, that is to say that the smaller the $K m$ value, the greater affinity between metabolic enzyme and nuciferine. In this experiment, the $K m$ value of nuciferine in mouse liver microsome was the smallest, which suggested that the affinity between mouse liver microsome enzyme and nuciferine was the highest and its metabolism ability was the strongest. Then the deep metabolism mechanism needed to more study in future.

\section{Conclusion}

The calculated results of pharmacokinetics parameters showed that the fast absorption of nuciferine exhibited in rabbits, rats and mice, while the elimination was relatively slow. Compared with rabbit and rat, the nuciferine elimination was fastest in mice. The $K m$ value of nuciferine metabolism in vitro was least in mice liver microsome, which suggested that the fastest metabolism of nuciferine existed in mice liver. Therefore, the pharmacokinetics characteristics of nuciferine in different species were significantly different, the elimination of nuciferine is the fastest in mice and the slowest in rabbits, which was in line with the in vitro metabolism trends by liver microsome from different species.

\section{Acknowledgement}

This work was supported financially by the National Natural Science Foundation of China (31100499 and 31672462), the Major Science and Technology Projects in Zhejiang Province (2020C02045) and Zhejiang Science and Technology Commissioner Team Project.

\section{Author's Contributions}

Dong Xiao-Chen: Complete experiments and writing. Liu Ming-Qi, Liu Jun and Guan Feng: Design of part experiments.

Xu Ai-Chun and Zhao Jin: Guide of part experiments.

Ge Jian: Design and guide experiments.

\section{Ethics}

The authors declare their responsibility for any ethical issues that may arise after the publication of this manuscript.

\section{References}

Feng, Y., Wan, J., Chen, B., Zhu, Y., Firempong, C. K., Feng, C., ... \& Yu, J. (2020). In Vitro Metabolic Profiling of Periplogenin in Rat Liver Microsomes and its Associated Enzyme-kinetic Evaluation. Current Pharmaceutical Analysis, 16(5), 504-512. https://www.ingentaconnect.com/contentone/ben/cp a/2020/00000016/00000005/art00007 
Gu, S. Y., Zhu, G. H., Kang, L., Li, X. Y., \& Liu, G. L. (2014). Pharmacokinetics of nuciferine in rats. Chinese Journal of Clinical Pharmacology and Therapeutics, $19(2), \quad 171$. http://manu41.magtech.com.cn/Jweb_clyl/EN/abstra ct/abstract9174.shtml

He, R., Fan, J., Chen, R., Guo, D., Zhao, M., Zhang, Z., ... \& Zhang, W. (2021). Stereoselective in vitro metabolism of cyproconazole in rat liver microsomes and identification of major metabolites. Chemosphere, 264, 128495. https://doi.org/10.1016/j.chemosphere.2020.128495

Li, M. Y., \& Xu, Z. T. (2007). The inhibition of dentifrice containing the lotus leaf-derived inhibitor on periodontitis-related bacteria in vitro. International Dental Journal, 57(5), 303-306. https://doi.org/10.1111/j.1875-595X.2007.tb00137.x

Li, Z., Chen, Y., An, T., Liu, P., Zhu, J., Yang, H., ... \& Yang, X. (2019). Nuciferine inhibits the progression of glioblastoma by suppressing the SOX2AKT/STAT3-Slug signaling pathway. Journal of Experimental and Clinical Cancer Research, 38(1), 1-15. https://doi.org/10.1186/s13046-019-1134-y

Liu, H., Hao, Y., Zhu, X. Y., Wang, M., \& Zhang, D. Q. (2010). Determination of nuciferine in rat plasma by HPLC and its application to pharmacokinetic study. Chinese Journal of Experimental Traditional Medical Formulae, 12. https://en.cnki.com.cn/Article_en/CJFDTotalZSFX201012059.htm

Liu, W., Yi, D. D., Guo, J. L., Xiang, Z. X., Deng, L. F., \& He, L. (2015). Nuciferine, extracted from Nelumbo nucifera Gaertn, inhibits tumor-promoting effect of nicotine involving $\mathrm{Wnt} / \beta$-catenin signaling in non-small cell lung cancer. Journal of Ethnopharmacology, 165, 83-93. https://doi.org/10.1016/j.jep.2015.02.015

Lu, Y. L., He, Y. Q., Wang, M., Zhang, L., Yang, L., Wang, Z. T., \& Ji, G. (2010). Characterization of nuciferine metabolism by $\mathrm{P} 450$ enzymes and uridine diphosphate glucuronosyltransferases in liver microsome from humans and animals. Acta Pharmacologica Sinica, 31(12), 1635-1642. https://doi.org/10.1038/aps.2010.172
Ma, C., Li, G., He, Y., Xu, B., Mi, X., Wang, H., \& Wang, Z. (2015). Pronuciferine and nuciferine inhibit lipogenesis in 3T3-L1 adipocytes by activating the AMPK signaling pathway. Life Sciences, 136, 120 125. https://doi.org/10.1016/j.lfs.2015.07.001

Ma, Z. C., Wang, Y. G., Tan, H. L., Liang, Q. D., Xiao, C. R., Tang, X. L., \& Gao, Y. (2016). The interaction between traditional Chinese medicine and liver drug metabolism enzymes. World Chinese Journal of Digestology, 24 (7), 994-1001. https://doi.org/10.11569/wcjd.v24.i7.994

Wang, Y. X., Liu, B., Shi, R. B., Wang, W., \& Chen, Y. P. (2008). Determination of nuciferine in beagle dog plasma by RP-HPLC and research on its pharmacokinetics. Chinese Journal of Pharmaceutical Analysis, 28(9), 1418-1421. https://www.ingentaconnect.com/content/jpa/cjpa/20 08/00000028/00000009/art00003

Xia, T., Wang, C. Q., Chen, H., \& Pan J. (2019). Metabolic pathway and enzymatic kinetics of Bletilla striata in liver microsome in vitro. Chinese Pharmacy, 30(10), 1316-1320.

Xu, H., Wang, L., Yan, K., Zhu, H., Pan, H., Yang, H., ... \& Gong, F. (2021). Nuciferine Inhibited the Differentiation and Lipid Accumulation of 3T3-L1 Preadipocytes by Regulating the Expression of Lipogenic Genes and Adipokines. Frontiers in pharmacology, $12, \quad 338$. https://www.frontiersin.org/articles/10.3389/fphar .2021.632236/full

You, J. S., Lee, Y. J., Kim, K. S., Kim, S. H., \& Chang, K. J. (2014). Ethanol extract of lotus (Nelumbo nucifera) root exhibits an anti-adipogenic effect in human preadipocytes and anti-obesity and anti-oxidant effects in rats fed a high-fat diet. Nutrition Research, 34(3), 258-267. https://doi.org/10.1016/j.nutres.2014.01.003

Zhang, C., Deng, J., Liu, D., Tuo, X., Xiao, L., Lai, B., ... \& Wang, N. (2018). Nuciferine ameliorates hepatic steatosis in high-fat diet/streptozocin-induced diabetic mice through a PPAR $\alpha /$ PPAR $\gamma$ coactivator- $1 \alpha$ pathway. British Journal of Pharmacology, 175(22), 4218-4228. https://doi.org/10.1111/bph.14482 